\title{
A survey on the use of native knowledge to make the management of water resources sustainable (sample: North Eastern part of I.R. Iran)
}

\author{
A. A. Kadivar \\ Payame Nour University of Mashhad, Iran
}

\begin{abstract}
The world has begun the third millennium while the different activities of humans have been affected by water stress and the scarcity of water in the world. This problem will result, in the not very distant future, in water conflicts and war among nations in most regions of the world particularly those in arid and semiarid regions. Iran, a country in the Middle East, in addition to aridity and water stress, has also been involved in problems of water management. In recent years, government interference in water management has caused the people to distance themselves from their principal participatory role in water management. The withdrawal of water users from their responsibility has made the problems more complicated in Iran, particularly in the North Eastern part of Iran. This research has been undertaken using a descriptive and analytical method with documents and field studies on problems resulting from government involvement in water management to find the key solutions from native knowledge to reduce the problems. The result of our investigation shows that, despite the half century government involvement in water resource management without acknowledging the role of creative cooperation of people, there is still an acceptable social investment that could be used in water resource management. The other result of this research is that native knowledge, if used, could now solve the problems that sustainability could be achieved in the management of soil and water resources. Keywords: management of water resources, social investment, native knowledge, North Eastern part of Iran.
\end{abstract}




\section{Introduction}

People in arid lands have a better understanding of the word WATER as a vital material for the basis of life. Therefore the first signs of physical and social structures can be found in arid areas. Ecology investigation shows that the social and physical water structures belong to the historical construction of the Middle East [1].

Iranians, like other Middle East communities, were the tribes who developed valuable effects on water resource management and water utilization. Gublo writes about water dam construction in Iran: Iranian farmers used Qanat to bring out underground water [2].

Accompanied by the construction of physical structures, systems and working group organizations matched with water resource management have been formed. Based on the field studies and numerous research including, among others, Lampton [3], Wittfogel [4], Petrovsky [5], Sodagar [6] and SafiNejad [7], water management and water distribution systems in Iran had been the most accurate and the highest level of water participatory management in the past.

During the last fifty years, because of the development of governmental bureaucracy in Iran, the traditional water system management and water distribution lost its strengths and importance. During this period population growth accompanied by the disability of governmental management, brought about different water problems such as water stress and falling of underground water levels as well as the formation of critical water resources.

Now the government officials, accepting their weak management behavior toward water issues in the last decades, have stated their interest in organizing people cooperatives to solve water problems.

This paper tries to explain the mechanism of using native knowledge and people's capacity of cooperation for the cooperative management of water resources so that we can reach sustainable cooperative water management.

\section{Presentation of research issue}

At the beginning of the third millennium, despite the fast progress of humans' finding new scientific facts, man had been confronted with environmental and human justice with serious challenges.

Even with natural difficulties, different studies in the furthest points of the Middle East and Iran have been undertaken at a national and international level [8]. These revealed a lot of misdoings particularly in water management that resulted in inefficiency and low efficiency in water use, particularly in the North Eastern part of Iran.

Based on Jihad Keshavarzi (an organization for agriculture) water efficiency data in the North East of Iran in 2006 has been 30 to 40 percent, that is certainly less than the world mean [9]. 
Now, after half of a century, government organizations are looking for people cooperation to transfer water management to people participatory organizations.

In the last decade, different mechanism and guidelines for the reduction of problems and for the optimum use of water resources has been developed including the establishment of water user cooperations or water users associations in the North Eastern part of Iran [10].

First analysis of the subject made by Kadivar [11] shows that there are still serious problems with the newly established water association. There is no new result of progress in economic, social and environment for better activity of participatory organization [11]. Concerning all the problems and issues, some referred to above; this paper will answer the following questions:

1- What are the issues and problems of governmental water management which has caused the critical situation in the water resources of the North Eastern part of Iran?

2- Which kinds of problems and obstacles are there in transferring the water management to cooperatives in the North Eastern part of Iran?

3- To make the water management sustainable in the North East of Iran how could we use native knowledge and experience of working together in Iran?

\section{Research method}

Descriptive and analytic method accompanied by the field and documents study was used to distinguish and analyze the problems created by governmental water management. Guidelines for the utilization of native knowledge to reduce the problems were also used.

The author of this article, in addition to the mentioned efforts, has managed to establish more than 10 Water Users Cooperatives (WUCs) in the North East of Iran so that he could be familiarized with structures and native knowledge of native people of these lands.

\subsection{The framework of theoretical investigation}

After some decades that management and programming for growth and economic development were in government hands, and centralized up side decision making for people was the procedure, in the 1990s the world consensus was formed in favor of participatory irrigation management (PIM) and the decrease of government involvement in resource management, particularly in water. Sowdagar believes that in the Iran plateau, before beginning to develop agriculture, water distribution on a large scale should have been developed.

Water distribution in dry and semi dry lands should be accompanied by flood control and reserving the flood water and finally transferring the water to agricultural fields. To organize and implement these affairs, there is a need for large and capable organizations with centralized management. But to do so the case will result in a powerful layer of bureaucracy. 
Working on a farm, in the dry villages of Iran, you need a lot of solutions for solving irrigation problems. There is no doubt that without solving the water problems, particularly without implementing a meaningful system to irrigation, getting profit from the land is impossible.

Throughout the whole history of Persia the issue of water management and investment in irrigation was always in open discussion. As an example we see that in an inscription of Khajeh Rashidaldin Fazlolah the issue of irrigation and construction of canals and dams and other water structures were very important [5].

In the present century, the involvement of the governments and native governors in water issues has been spread widely in the world. At the same time, development theories have only been glanced at, even in opposition to the social relationship, in economic development. Recommendations and policies provided by them were not very suitable.

For example in the 1950s and 1960s, social relations and traditional behaviors were supposed to somehow prevent development [12].

In this relation, More says that when modernizing theorizing explained the breakdown or death of investment, the most important point at the center of their attentions were the social relation as an obstacle, so that in one of the valid documents of the time, belonging to the UN in 1951, it says if development is to progress, old philosophies should be thrown away.

They believed that to progress development: old social institutions should be broken, the chains of faith and races should be smashed into pieces and those numerous people who could not be modernized step by step, be deprived of welfare and relaxed life and they should accept the disappointment [13].

In this connection Misra says: one of the main irregularities extended into programming of regional development, is the low concern of the people and accounting more than needs and emphasis on economic growth [14]. This thinking and approach in Iran, during last the 50 years, has caused the omission of the role of people and their native knowledge from economic and social relationship in Iran society and in all fields of activity, particularly the management of natural resources including water.

In this period, by the formation of a developed governmental bureaucracy, most of the social and economic affairs were given to governmental bodies, and did not observe the people's dignity in the system of decision making and execution of development projects including water projects (Bale [15]; IWMI [16]; WCD [17]; Maestu [18]). Most of the consolidated articles presented in China Vehan at 1994 and as for Iran, the articles and books of the National Committee for Irrigation and Drainage, states that a view of governmental approach and removing the people from water resource management, reflects the government's failure in the attraction of people cooperation and investment.

Today, after the government failure in water resource management and inability of the government in the solution of water problems, the government has decided to return to people cooperation and their participation toward water resources issues. So it is seen that from the late decades of 1980, particularly in 
1990, the theory of people participation and investment in water resource management and irrigation program is widespread all over the world.

In the new paradigm of looking forward to people's dignity particularly to people relationship and society communication network under the title of: "concept of social investment" and followed by "participation", is presented.

Theory of society investment is very understandable. The main concept could be said in three words that are "communication is important ".

People together do their hard works with cooperation that without connection and cooperation, an individual could not do that. People through numerous networks of connection are connected together and mostly have joint values with the members of other networks so that the total networks of people communications make a source that is a kind of investment [19].

Three main pioneers who formulated the new theory of society investment are Boardieu, Colmonand, Putnam.

All three theorizing scientists believe that society investment includes: personal communication, mutual action and reaction, accompanied with collection of joint values in these connections.

From this point, Punam has a great contribution to introduce this word. $\mathrm{He}$ was the person who introduced this nearly unknown word of economy and social meaning into the common literature. The abstract definition of Putnam for society invests is: "characteristics of social organization, such as confidence, criterions and networks which through some facilities of co ordinations can progress the efficiency of society" [20].

Society investments and participation have been changed to a world economy development. Tens of research studies on rural development have shown that a powerful network of local people associations has the same importance as physical, technological and availability to suitable market prices.

As Astrom, the political scientist, resulting from his research, says why some cooperation for the control of joint resources such as lawn and water resources has not been successful but others have been successful. In this field, social investment has an important role. Against this, involvement of government that ignores the social infrastructures or weakens it may have undesirable results [21].

Today, attention to social investment, particularly to the special guideline of participation is the main column of sustainable development. This is the guideline of people participation which determines the role of local societies in sustainable development as a determination factor.

\section{Location area for study}

The area selected for study is in the North Eastern part of Iran including from 36 $35 \mathrm{~N}$ latitude to $3857 \mathrm{~N}$ and from 5925 longitude to 6059 longitude. The mean for total yearly rain is $250 \mathrm{~mm}$. the sum of mean precipitation differs from $400 \mathrm{~mm}$ in lands with $3000 \mathrm{~m}$ height to the minimum precipitation of $150 \mathrm{~mm}$ for low level plain [22]. 


\section{Discussion}

The water sources in the North East of Iran have passed two periods of water management in the historical past. And now, a new period of management is forming. These three periods are as follows:
A. The historical traditional period before 1950;
B. The modern period from 1950 to the end of 1990 ;
C. The period of postmodern from the end of 1990 until now.

A. in the traditional period, people worked together with a systematic cooperative management and with high efficiency utilization of soil and water. These old cooperatives in the North part of Iran were called SAHRA (desert). The field work was distributed among SAHRA members as to their expertise. All members of SAHRA were nominated for special work for one year under control of a unit of one management.

At the beginning of cultivation year (September), the managers in SAHRA cooperative system explained the way of soil and water utilization, the amount and procedure of cultivation allocated for each product. This procedure of management and working group is shown in the following:

High dignity owner

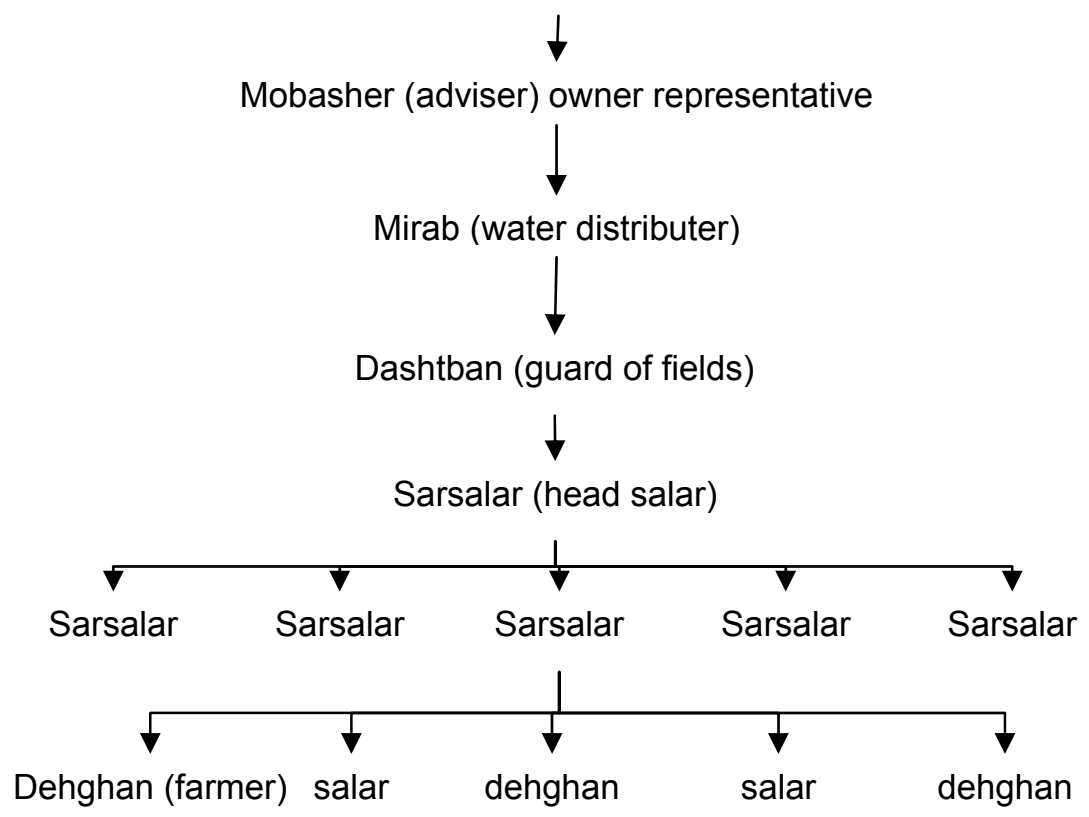

Figure 1: The chain of dignity priority in WUCs. 
As in figure. 1, work and responsibility has been a suitable efficiency in the old system of water users' cooperatives. The success of traditional old WUCs is having a complete regular structure based on decision making in a chain of managing from the top down.

B. with the end of second world war and independency of most of the colonies and also with the formation of independent governments in different parts of the world, the governmental organizations and foundations were formed step by step, so that to control successfully the management of different environmental, social and economic situations including water issues became possible.

This kind of governmental involvement in water happened also in the North Eastern part of Iran where many old and traditional WUCs were working successfully. In this part of Iran, too, the government took the management and responsibility of water resources and irrigation in its hand.

In the period of governmental water management, new and modern technologies were used to modernize irrigation system. In spite of using modern technology in irrigation systems, but to put away the participation of farmers and WUCs, was an end to justice and people cooperation and this resulted in many problems in the utilization of water, particularly in using the groundwater in the plain of metropolitan of Mashhad city. In a 20 year period, the water table of this plain (Mashhad plain) fell extensively. Figure 2 shows the fall of underground level of water in the Mashhad plain.

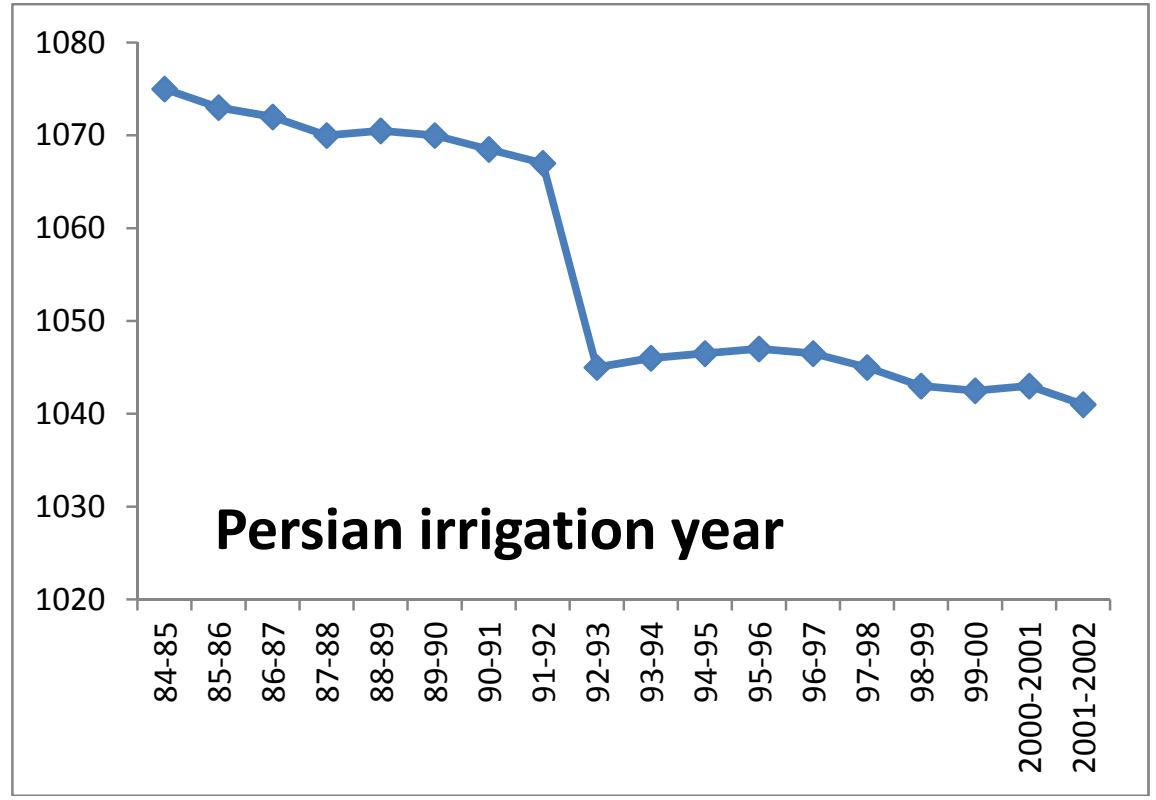

Figure 2: $\quad$ The fall of the water table in the Mashhad plain. 
C. After the clearance of the failure of governmental involvement in water resource management, a new discussion was brought in the North Eastern part of Iran and that was restoration of the water again, user cooperatives and to transfer the water management to WUCs in the 1990s.

Now, the main question in the North Eastern part of Iran is how to use the native knowledge and social investment in Iran which had been pushed away in this country from four decades ago. Evaluation on a different area of our research location done by the field study method, shows that there is much capacity for WUC cooperation for joint activities in social groups to reach successful participatory management. In this research, selecting a representative society, the views of different water users and their willingness for water cooperation has been asked. The result of this investigation is shown in figure 3 .

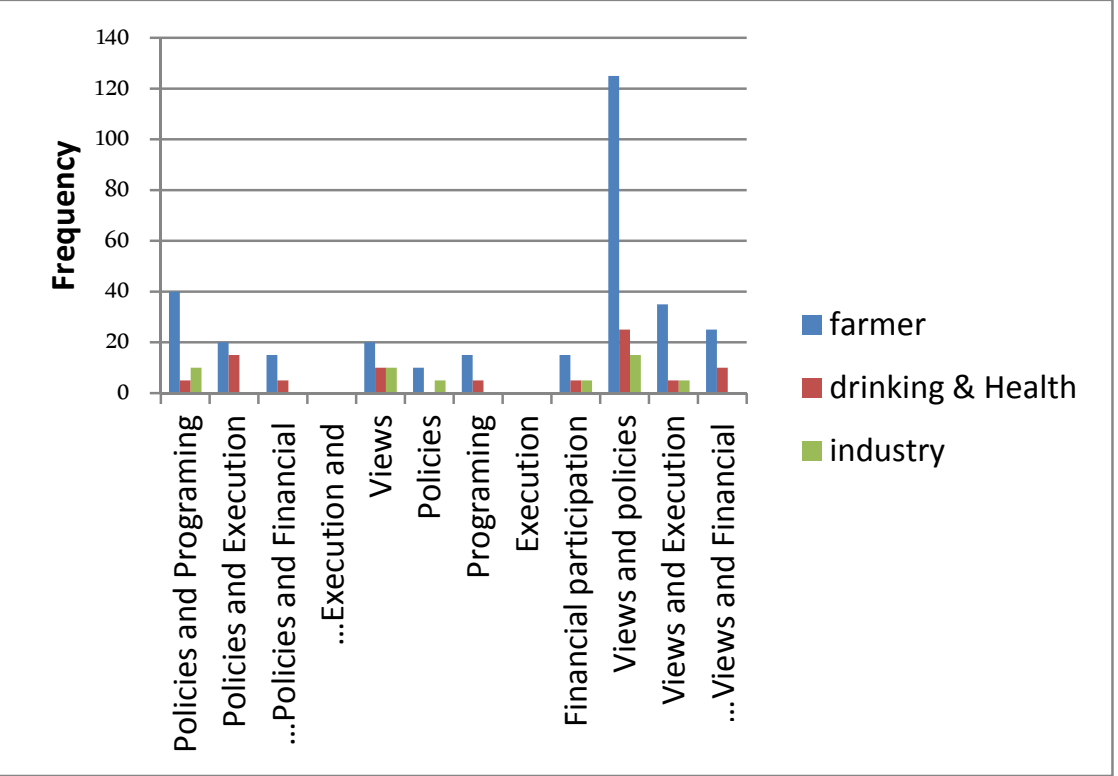

Figure 3: Frequency of level of WUC participation with distinction between job working groups.

Table 1 shows that from 606 statistical societies 449 persons (74/1\%) have answered the questioner. The majority of answers (36/3 \%) mentioned their level of participation in management and programming at the level of questioner and policies that from this amount $28 / 1$ were farmers, $5 / 6 \%$ of drinking and healthy water users, and $3.4 \%$ were industrial workers.

The result of table 2 shows that calculated K2 (37.268) with a degree of freedom of 33 and level of confidence $95 \%$ is smaller than critical K2. As a result 0 hypothesis is accepted and opposed hypotheses are rejected. There was no meaningful difference in comparison between levels of participation in statistics society with different job working group. 
Table 1: Frequency distribution of participatory interest among water users according to different job groups.

\begin{tabular}{|c|c|c|c|c|c|c|c|c|}
\hline \multicolumn{2}{|c|}{ Total } & \multicolumn{2}{|c|}{$\begin{array}{l}\text { Industrial } \\
\text { users }\end{array}$} & \multicolumn{2}{|c|}{$\begin{array}{l}\text { Drinking } \\
\text { and health } \\
\text { users }\end{array}$} & \multicolumn{2}{|c|}{ Farmer } & \multirow{2}{*}{$\begin{array}{l}\text { Job working group } \\
\text { Analysis }\end{array}$} \\
\hline 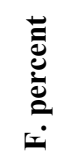 & 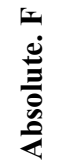 & 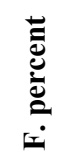 & 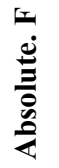 & 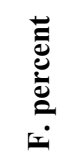 & 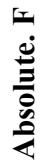 & 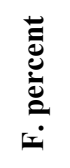 & 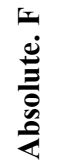 & \\
\hline 8.6 & 40 & 2.2 & 10 & 2.2 & 10 & 4.2 & 20 & Views \\
\hline 3.3 & 15 & 1.2 & 10 & 0 & 0 & 2.2 & 10 & Policies \\
\hline 5.5 & 25 & 0 & 0 & 1.2 & 5 & 4.4 & 15 & Programming \\
\hline 0 & & & & 0 & 0 & 0 & 0 & Execution \\
\hline 4.4 & 25 & 0 & 5 & 1.2 & 5 & 3.3 & 15 & Financial participation \\
\hline 36.1 & 185 & 3.4 & 15 & 5.6 & 25 & 28.1 & 125 & Views and policies \\
\hline 10.1 & 45 & 2.2 & 5 & 1.2 & 5 & 7.8 & 35 & Views and Execution \\
\hline 7.8 & 35 & 0 & 0 & 2.2 & 10 & 5.6 & 25 & Views and Financial \\
\hline 13.4 & 75 & 2.2 & 9 & 1.2 & 5 & 10 & 40 & Policies and Programming \\
\hline 7.9 & 40 & 0 & 0 & 3.4 & 15 & 4.5 & 20 & Policies and Execution \\
\hline 4.5 & 20 & 0 & 0 & 1.2 & 5 & 3.3 & 15 & $\begin{array}{l}\text { Policies and Financial } \\
\text { participation }\end{array}$ \\
\hline$\%$ & & 0 & 0 & 0 & & 0 & 0 & $\begin{array}{l}\text { Execution and Financial } \\
\text { participation }\end{array}$ \\
\hline 100 & 449 & 10.1 & 44 & 19.1 & 85 & 70.8 & 320 & Total \\
\hline
\end{tabular}

Table 2: $\quad$ Statistical test for comparison the level of WUC participation.

\begin{tabular}{|c|c|c|}
\hline Statistical test K2 & degree of freedom & level of meaningfulness \\
\hline 0.279 & 33 & 37.268 \\
\hline
\end{tabular}

\section{Conclusion}

The result of all discussion shows that most regions of the developing countries such as North Eastern Iran are passing an important and sensitive transfer from governmental management to people water managing.

The main reason is that traditional management has vanished completely, the governmental and centralized management experienced a failure and as a result a great critical situation in water and soil use exists all over the regions.

These problems made the government, people and groups of environment protection sensitive toward the problems. So all policy makers are in search of a 
model to using more efficient managing of water, using the world experiences in this matter, to alleviate and decrease the problems.

In this way, participatory management is a suitable selection to solve the problems. Participatory management has the capacity to solve most of the problems if the native knowledge and people capacity, with existing readiness, were used.

The native knowledge, because of its sustainable mechanism that is confident based on local capacity and also capability to be matched with modern knowledge, would be a safe way to make the utilization of water resources more sustainable.

\section{References}

[1] Mostert, E. The challenge of public participation, water policy. 5, p. 159$160,2003$.

[2] Goblot, H, Qanats water to achieve technical translation, M. H, Papoli and A. Sarvqad, p. 23-27, 1371.

[3] Lampton, A. K. S, the owner and planter der Iran, translated by M. Amiri, Scientific and Cultural Center Publications, p. 423-463,1362.

[4] Wittfogel, K, Oriental Despotism, Yale University, p. 29-32, 1961.

[5] Petrovsky, A. The Union of Iranian translated by Ajand, A. Niloofar Publications, p. 341-347, Tehran 1359.

[6] Sodagar, M. The Lord of the Rural System in Iran, Pajand Publication, p. 14-19, Tehran, 1359.

[7] Safi-Nejad, J, Bone, (Traditional Farming Systems in Iran), Amir Kabir Publications, p. 54-61, Tehran, 1364.

[8] Pourzand, A. Background and current situation of consumer organizations and associations create practical experience, Tehran, 1378.

[9] Jahad Investigations Center Agricultural Khorasan Razavi, Crops Agricultural Board Fshardh, 1368.

[10] Toossab Consulting, Co. Summary of dams and Bydvaz, 1387.

[11] Kadivar. A.A. Effects of check dams in the river basin, Ferdowsi University doctoral dissertation, 138.

[12] Vlkak M. and Dypana. R. Social capital and its implications for development theory, research and policy, Proceedings of the trust, social capital, democracy and development, translation by A. Khakbaz, effort, K. Tajbakhsh, shraze, publication, Tehran,1385.

[13] http://www.harmonicop.uniosnabtaeck/spain

[14] Misra. A. R. P, Regional Development Planning in search of meaning, Journal of Planning and Development, P 124- 145, No. I, summer 1366.

[15] Bale. J. Smith. D. (1989): Ecology and Development in the Third international water management institute (1994): irrigation management transfer, China, 248-256.

[16] International Water Management Institute (1994): irrigation management transfer, China.

[17] http://www.dams.org/reports 
[18] http://www.gap.gov.tr/tarkish/tarim/wsm2.pdf

[19] Najafi. M, Establishing Water User Associations for Management Operation in Moghan irrigation System, 4th Regional Conference Participatory Irrigation Management, 2007, Tehran.

[20] Patnam. R. Social capital and its implications for development theory, research and policy, Proceedings of the trust, social capital, democracy and development, translation by A. Khakbaz, effort, K. Tajbakhsh, shraze, publication, Tehran, 1385.

[21] Field. J, social capital is and why it is important, translated by, Motaghi. J, Financial Research Institute, Social Security: P 34- 38, Tehran, 1385.

[22] Khorasan Razavi Department of Statistics and Planning, GIS maps of the area, 1385. 